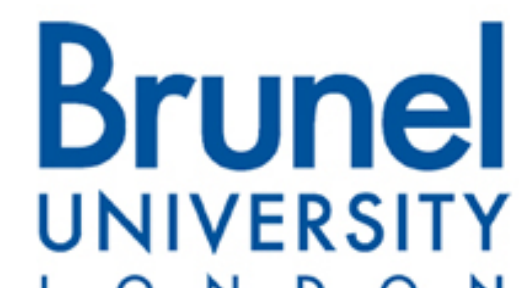

L O N D O N

Department of

Economics and Finance

Working Paper No. 13-09

Guglielmo Maria Caporale and Luis A. Gil-Alana

$\frac{1}{2}$

a

Long Memory and Fractional I ntegration in High Frequency Data on the US Dollar British Pound Spot Exchange Rate

April 2013

http://www.brunel.ac.uk/economics 


\title{
LONG MEMORY AND FRACTIONAL INTEGRATION \\ IN HIGH FREQUENCY DATA \\ ON THE US DOLLAR / BRITISH POUND \\ SPOT EXCHANGE RATE
}

\section{Guglielmo Maria Caporale \\ Brunel University, London}

\author{
Luis A. Gil-Alana ${ }^{\text {b }}$ \\ University of Navarra
}

March 2013

\begin{abstract}
This paper analyses the long-memory properties of a high-frequency financial time series dataset. It focuses on temporal aggregation and other features of the data, and how they might affect the degree of dependence of the series. Fractional integration or I(d) models are estimated with a variety of specifications for the error term. In brief, we find evidence that a lower degree of integration is associated with lower data frequencies. In particular, when the data are collected every 10 minutes there are several cases with values of $\mathrm{d}$ strictly smaller than 1, implying mean-reverting behaviour; however, for higher data frequencies the unit root null cannot be rejected. This holds for all four series examined, namely Open, High, Low and Last observations for the US dollar / British pound spot exchange rate and for different sample periods.
\end{abstract}

Keywords: High frequency data; long memory; volatility persistence; structural breaks.

JEL Classification: C22, F31

a Corresponding author. Department of Economics and Finance, and Centre for Empirical Finance, Brunel University, London, UB8 3PH, UK. Tel.: +44 (0)1895 266713. Fax: +44 (0)1895 269770. Email: Guglielmo-Maria.Caporale@,brunel.ac.uk

\footnotetext{
$\mathrm{b}$ The second-named author gratefully acknowledges financial support from the Ministry of Education of Spain (ECO2011-2014 - 28196 - ECON Y FINANZAS, Spain) and from a Jeronimo de Ayanz project of the Government of Navarra. We are also grateful to Walter Kramer and other participants in the Symposium on high frequency data in empirical finance, Technische Universitat Dortmund, Dortmund, Germany, 1-2 July 2010.
} 


\section{Introduction}

The Efficient Market Hypothesis (EMH) in its weak form rules out the possibility of abnormal systematic profits over and above transaction costs and risk premia, as prices should fully reflect available information (see Fama, 1970). The implication is that stock prices should follow a random walk process, which implies unpredictable returns (see Summers, 1986). Therefore, a finding of mean reversion in stock prices is seen as inconsistent with equilibrium asset pricing models (see, e.g., Poterba and Summers, 1988 and Fama and French, 1988). A large number of studies have been carried out to establish whether (log-)prices are indeed I(1) and, consequently, stock market returns I(0) series, although business cycle variation and short-range dependence might also lead to a rejection of long memory in stock prices (see Lo, 1991). However, as we argued in Caporale and Gil-Alana (2002), the assumptions imposed by standard unit root tests might be too restrictive, and the possibility of fractional orders of integration with a slow rate of decay should be considered. Therefore that study performed tests allowing for fractional alternatives and incorporating the $\mathrm{I}(0)$ and the $\mathrm{I}(1)$ models as particular cases of interest, and found that US real stock returns are close to being I(0) (note that if shocks are weakly autocorrelated, markets will not be efficient).

A subsequent contribution (see Caporale and Gil-Alana, 2007) decomposed the stochastic process followed by US stock prices into a long-run component described by the fractional differencing parameter (d) and a short-run (ARMA) structure. Finally, in Caporale and Gil-Alana (2008) we introduced a more general model which, instead of considering exclusively the component affecting the long-run or zero frequency, also takes into account the cyclical structure. Specifically, a procedure was applied which allows to test simultaneously for unit roots with possibly fractional orders of integration at both the zero and the cyclical frequencies. Modelling simultaneously with long range 
dependence the zero and the cyclical frequencies can solve at least to some extent the problem of misspecification that might arise with respect to these two frequencies.

However, the fractional differencing parameter may be very sensitive to the data frequency used in the analysis. In fact, it has often been claimed that aggregation is behind fractional integration: Robinson (1978) and Granger (1980) showed that the aggregation of heterogeneous individual AR processes may produce fractional integration. On the other hand, it is well known that temporal aggregation leads to finite sample biases in the estimates of the fractional differencing parameter (see, e.g. Souza and Smith, 2002). ${ }^{1}$ This is the main issue that will be investigated in the present study by using a high frequency dataset on the US dollar-British pound spot exchange rate collected every 1, 2, 3, 5, and 10 minutes. As in Caporale and Gil-Alana (2008), we start the analysis using a general long memory model that incorporates poles at both the zero and a cyclical frequency; however, since the evidence clearly suggested an order of integration not significantly different from zero for the cyclical frequency, we then focus exclusively on the long run or zero frequency.

Fractional integration in exchange rates markets has been examined in various papers, many of them testing the Purchasing Power Parity (PPP) condition, which occupies a central place in international economics. Applying R/S techniques to daily rates for the British pound, French franc and Deutsche mark, Booth, Kaen and Koveos (1982) found positive memory during the flexible exchange rate period (1973-1979) but negative one (i.e., anti-persistence) during the fixed exchange rate period (1965-1971). Later, Cheung (1993) also found evidence of long memory behaviour in foreign exchange markets during the managed floating regime. On the other hand, Baum,

\footnotetext{
${ }^{1}$ Note, however, that Souza and Smith (2002) consider systematic sampling only, while the present work focuses on returns. See also Souza (2005) and Hassler (2011) for other papers on fractional integration under temporal aggregation.
} 
Barkoulas and Caglayan (1999) estimated fractional ARIMA (ARFIMA) models for real exchange rates in the post-Bretton Woods era and found almost no evidence to support long run PPP. Additional studies on exchange rate dynamics using fractional integration are those by Crato and Ray (2000), Wang (2004), Dufrenot et al. (2006, 2008) and Aloy et al. (2011) among others. All these papers, however, focus on low frequency (mainly quarterly) data, and do not examine the case of high frequency (intraday) data.

The present study focuses on the case of spot exchange rates with the aim of gaining some insights into the interaction between fractional integration and high frequency data. The results suggest that lower degrees of memory are associated with lower data frequencies. The layout of the paper is as follows. Section 2 describes the econometric methodology used. Section 3 provides details of the data and discusses the empirical results. Section 4 summarises the main findings and offers some concluding remarks.

\section{Methodology}

There are two definitions of long memory, one in the frequency domain and the other in the time domain. Let us consider a zero-mean covariance stationary process $\left\{x_{t}\right.$, $t=0, \pm 1, \ldots\}$ with autocovariance function $\gamma_{u}=E\left(x_{t} x_{t+u}\right)$. The time domain definition of long memory states that:

$$
\sum_{u=-\infty}^{\infty}\left|\gamma_{u}\right|=\infty
$$

Assume that $x_{t}$ has an absolutely continuous spectral distribution, so that it has a spectral density function, $f(\lambda)$; according to the frequency domain definition of long memory the spectral density function is unbounded at some frequency $\lambda$ in the interval $[0, \pi)$, i.e., 


$$
f(\lambda) \rightarrow \infty \quad \text { as } \quad \lambda \rightarrow \lambda^{*}, \quad \lambda^{*} \in[0, \pi]
$$

Most of the existing empirical literature considers the case when the singularity or pole in the spectrum occurs at the zero frequency. This is the standard case of $I(d)$ models of the form:

$$
(1-L)^{d} x_{t}=u_{t}, \quad t=0, \pm 1, \ldots
$$

with $\mathrm{x}_{\mathrm{t}}=0$ for $\mathrm{t} \leq 0$, and $\mathrm{d}>0$, where $L$ is the lag-operator $\left(L x_{t}=x_{t-1}\right)$ and $u_{t}$ is $I(0)$, being defined in this context as a covariance stationary process with a spectral density function that is positive and finite at any frequency. This includes a wide range of model specifications such as the white noise, the stationary autoregression (AR), moving average (MA), stationary ARMA etc. ${ }^{2}$

Note that the parameter $d$ plays a crucial role in describing the degree of dependence of the series. Specifically, if $d=0$ in (1), $x_{t}=u_{t}$, and the series is $I(0)$, potentially including ARMA structures with the autocorrelations decaying at an exponential rate. If $\mathrm{d}$ belongs to the interval $(0,0.5)$, the series is still covariance stationary but the autocorrelations take longer to disappear than in the $\mathrm{I}(0)$ case. If $\mathrm{d}$ is in the interval $[0.5,1)$, the series is no longer covariance stationary; however, it is still mean-reverting with shocks affecting it disappearing in the long run. Finally, if $d \geq 1$ the series is nonstationary and non-mean-reverting.

In this paper we analyse the long memory property of a high frequency financial dataset, noting that the fractional differencing parameter can change substantially depending on the data frequency employed. The methodology employed here to estimate the fractional differencing parameter is based on the Whittle function in the frequency domain (Dahlhaus, 1989). We also employ a testing procedure developed by

\footnotetext{
${ }^{2}$ If $u_{t}$ in (1) is an $\operatorname{ARMA}(p, q)$ process, $x_{t}$ is then said to follow a Fractionally Integrated ARMA or $\operatorname{ARFIMA}(p, d, q)$ model.
} 
Robinson (1994) allowing to test for any real value of $d$ in $I(d)$ models. This method is a Lagrange Multiplier (LM) procedure and is the most efficient one in the context of fractional integration. It tests the null hypothesis $H_{0}: d=d_{o}$ for any real value $d_{o}$, and the test statistic follows a standard (normal) limit distribution. Moreover this standard limit behavior holds independently of the inclusion of deterministic terms (like intercept and/or linear trends) and the specific modelling of the $I(0)$ error term $u_{t}$ in (1). The functional form of this method is specified in various empirical applications (Gil-Alana and Robinson, 1997; Gil-Alana, 2000; etc.). Alternatively, we could have employed Wald and LR test statistics against fractional alternatives with the same null and limit theory as the LM test of Robinson (1994). Lobato and Velasco (2007) essentially employed such a Wald testing procedure, although this method requires a consistent estimate of d, and therefore the LM test of Robinson (1994) seems computationally more attractive. Other methods, such as the one developed by Demetrescu, Kuzin and Hassler (2008), which have been shown to be robust with respect to even unconditional heteroscedasticity, were also implemented leading to practically the same results as those reported in the paper.

\section{Data and empirical results}

The data used for the analysis are taken from Reuters, and are intraday data at the 1, 2, 3, 5, 10-minute frequency. Specifically, the series examined is the spot nominal exchange rate of the US dollar pound vis-à-vis the British pound, for different sample periods with a duration of one and a half days. We only report the results for the period $13 / 05 / 2010(11: 47)-14 / 05 / 2010(21: 07)$, since those for other samples were very similar. ${ }^{3}$ In this way we avoid the potential bias due to sample dependency. We focus on

\footnotetext{
${ }^{3}$ We tried using five different sample periods over the years 2011 and 2012.
} 
samples of one day and a half on the basis of the computational time required when working with high frequency data in the context of long memory and fractional integration. However, we also conducted the analysis for a longer time series containing about 4,000 observations (or roughly a week) and the results were once again completely in line with those reported here. We examine four series: Open, High, Low and Last values of the exchange rate collected every minute, where High (Low) stands for the highest (lowest) price and Open (Last) for the initial (last) price observed in that time interval. The aim is to detect whether there exist anomalies in the behaviour of each of the series.

\section{[Insert Figures $1-4$ about here]}

Figure 1 shows plots of the four series. The corresponding returns, obtained as the first differences of the log-prices, are shown in Figure 2. Figures 3 and 4 display the correlograms and the periodograms of the return series. The values of the former seem to indicate that the original series may be $\mathrm{I}(1)$, suggesting the possibility of random walk behaviour; however, the presence of some significant values in the correlograms of the first differenced (logged) data, even at lags far away from zero might indicate weak autocorrelation and/or fractional integration. ${ }^{4}$

First, we estimate the value of $d$ for the four (logged) series at the highest frequency (i.e., with data collected each minute). For this purpose we consider the following model:

$$
y_{t}=\alpha+\beta t+x_{t} ; \quad(1-L)^{d} x_{t}=u_{t} ; \quad t=1,2, \ldots
$$

\footnotetext{
${ }^{4}$ It is debatable whether the four series should be modelled separately and treated in the same way. However, a simple visual inspection of Figure 1 shows that they move roughly in a very similar way.
} 
where $y_{t}$ is the time series observed, $\alpha$ and $\beta$ are the deterministic terms (an intercept and a linear time trend respectively), and $x_{t}$ is assumed to be $I(d)$, where $d$ can be any real number. Different assumptions will be made about the error term $u_{t}$ in (2). ${ }^{5}$

\section{[Insert Table 1 about here]}

Table 1 displays the results of the Whittle estimates of $d$ along with the $95 \%$ confidence interval of the non-rejection values according to Robinson's (1994) parametric approach. The error term $u_{t}$ is assumed to be a white noise in Table 1a, an AR(1) process in Table $1 \mathrm{~b}$, whilst it is specified using the exponential spectral model of Bloomfield (1973) in Table 1c. The latter is a non-parametric approach to modelling I(0) terms that produces autocorrelations decaying exponentially as in the AR(MA) case.

Table 1 shows the results of the estimated values of $d$, for the three standard cases of no regressors (i.e., $\alpha=\beta=0$ in (2)), an intercept ( $\alpha$ unknown and $\beta=0$ ), and an intercept with a linear time trend ( $\alpha$ and $\beta$ unknown). Starting with the case of white noise errors (Table 1a), it can be seen that for "Open" and "Last" the estimates are slightly below 1, though the unit root null cannot be rejected in any case. However, for "High" and "Low" the unit root hypothesis is rejected in favour of higher degrees of integration in the cases of an intercept and an intercept with a linear time trend. When allowing autocorrelation in the form of an $\mathrm{AR}(1)$ process (in Table 1b), the results vary depending on the inclusion or not of deterministic terms. Specifically, if no regressors are included in the regression model, $\mathrm{d}$ is found to be strictly higher than 1 for all four series; however, when including deterministic terms, the unit root null is almost never rejected. The only exception is "High" with a linear trend, when the estimated value of $\mathrm{d}$ is found to be 0.936 , and the interval excludes the unit root in favour of mean

\footnotetext{
5 The inclusion of a linear time trend in equation (2) may appear unrealistic in the context of financial data. Note, however that the time trend disappears in the long run as long as $\mathrm{d}>0$.
} 
reversion. When adopting the more general Bloomfield specification (Table 1c), the unit root null hypothesis is never rejected, clearly suggesting that the returns series are $\mathrm{I}(0)$. The t-values imply that the time trend coefficients are not statistically significant, whilst the intercepts are always significant. Thus, the model with an intercept seems to be the most adequate specification for these series.

\section{[Insert Figures 5 and 6 about here]}

Next we focus on the variance of the return series and examine the squared and absolute returns, which are used as proxies for volatility. These two measures have been widely employed in the financial literature to measure volatility. ${ }^{6}$ Plots of the absolute return series are displayed in Figure 5, while Figure 6 shows the squared returns. No structural breaks are apparent in any of these figures.

\section{[Insert Table 2 about here]}

Table 2 reports the estimates of $d$ for the absolute and squared returns under the assumption that the error term is white noise. Very similar results were obtained imposing weakly autocorrelated errors. The estimates are significantly positive in all cases, the values ranging between 0.142 ("Last" with an intercept) and 0.162 ("High" with no regressors) in case of the absolute returns, and between 0.096 ("Low" with a linear trend) and 0.109 ("Last" with an intercept) for the squared returns. When testing for autocorrelation in the error terms we do not find any evidence for it suggesting that the I(d) structure is sufficient to describe the time dependence in the absolute and squared returns. These results are consistent with those reported in the literature for lower frequency data, that is, the exchange rates appear to be I(1) implying that returns are $\mathrm{I}(0)$, and the associated volatility is $\mathrm{I}(\mathrm{d})$ with a positive and small value of $\mathrm{d}$.

\footnotetext{
${ }^{6}$ Absolute returns were employed among others by Ding et al. (1993), Granger and Ding (1996), Bollerslev and Wright (2000), Gil-Alana (2005), Sibbertsen (2004) and Cotter (2005), whereas squared returns were used in Lobato and Savin (1998), Gil-Alana (2003) and Cotter (2005). Using the "realized variance" produced very similar results.
} 
In the context of high frequency data, it is interesting to investigate if the same result holds as the distance between observations increases. For this purpose we examine again the long memory property of the same variables but now using data which are collected every $2,3,5$ and 10 minutes respectively.

\section{[Insert Table 3 about here]}

Table 3 displays the results using these lower frequencies assuming that the error term is a white noise process. Once more, when allowing for weak autocorrelation the estimation results for $\mathrm{d}$ were practically the same. Starting with data collected every 2 minutes (see Table 3a), it can be seen that the unit root null is almost never rejected. The only two exceptions are "Low" with an intercept, and with an intercept and a linear trend, where $d$ is strictly above 1 . Focusing now on the data collected every 3 minutes (Table $3 b$ ), it can be seen that the estimated values of $d$ are slightly smaller, and the unit root null hypothesis is never rejected. In general the estimates of $d$ are smaller by about 0.020 compared with those reported in Table 3a. Table 3c concerns the data collected every 5 minutes. Once more the values are smaller than in previous tables, and the same happens in Table $3 \mathrm{~d}$ which concerns data collected every 10 minutes. In this case, even values which are strictly smaller than 1 are found, implying a small degree of meanreverting behaviour.

\section{[Insert Tables 4 and 5 about here]}

Tables 4 and 5 display the estimates of $d$ for the absolute and squared returns series respectively, again assuming white noise errors. The results here are slightly more ambiguous as there is no monotonic decrease in the value of $\mathrm{d}$ as the time distance between the observations increases. For example, in the two cases of absolute and squared returns the highest values for "Last" occur for data collected every 3 minutes, and for "High" and "Low" for data collected every 5 minutes. This lack of monotonicity 
in the relationship between data frequency and the order of integration in the volatility processes is also found in the case of autocorrelated errors.

Finally, we employ a semiparametric method to estimate the values of $d$ for the series of interest, without assuming a functional form for the error term. We follow a procedure developed by Robinson (1995). This method is essentially a local 'Whittle estimator' in the frequency domain, which uses a band of frequencies that degenerates to zero. The estimator is implicitly defined by:

$$
\begin{gathered}
\hat{d}=\arg \min _{d}\left(\log \overline{C(d)}-2 d \frac{1}{m} \sum_{s=1}^{m} \log \lambda_{s}\right), \\
\overline{C(d)}=\frac{1}{m} \sum_{s=1}^{m} I\left(\lambda_{s}\right) \lambda_{s}^{2 d}, \quad \lambda_{s}=\frac{2 \pi s}{T}, \quad \frac{m}{T} \rightarrow 0,
\end{gathered}
$$

where $\mathrm{m}$ is a bandwidth number, and $\mathrm{I}\left(\lambda_{\mathrm{s}}\right)$ is the periodogram of the raw time series, $\mathrm{x}_{\mathrm{t}}$, given by:

$$
I\left(\lambda_{s}\right)=\frac{1}{2 \pi T}\left|\sum_{t=1}^{T} x_{t} e^{i \lambda_{s} t}\right|^{2},
$$

and $d \in(-0.5,0.5)$. Under finiteness of the fourth moment and other mild conditions, Robinson (1995) proved that:

$$
\sqrt{m}\left(\hat{d}-d_{o}\right) \rightarrow_{d} N(0,1 / 4) \quad \text { as } T \rightarrow \infty,
$$

where $d_{o}$ is the true value of $d$. This estimator is robust to a certain degree of conditional heteroscedasticity and is more efficient than other more recent semiparametric competitors.

\section{[Insert Figures 7 - 10 about here]}

The results based on the above approach are displayed in Figures $7-10$. Given the nonstationary nature of the series examined, first-differenced data are used for the estimation, then adding 1 to the estimated values to obtain the proper orders of 
integration of the series. ${ }^{7}$ It can be seen that the values are similar for the four series. Along with the estimates we also present the $95 \%$ confidence band corresponding to the I(1) hypothesis. We display the estimates for a range of values of the bandwidth parameter $\mathrm{m}$, first from $\mathrm{m}=1, \ldots, 100$, and then using a shorter interval, $\mathrm{m}=50,51, \ldots$, 100. The highest estimates correspond to the highest frequency, while the lowest ones correspond to the series with data collected every 10 minutes, giving further support to the hypothesis that lower degrees of dependence are associated with lower data frequencies. ${ }^{8}$ This is also consistent with the Monte Carlo experiments conducted in Caporale and Gil-Alana (2010), who find that, if the differencing parameter in the Data Generating Process has a fractional value, using data at a lower frequency increases the distortion in the estimation of $\mathrm{d}$, producing lower values and higher evidence of mean reversion. On the other hand, this is in contrast to Souza (2005) and other recent papers that show that temporal aggregation leaves the degree of integration unchanged (Souza, 2007, 2008a,b) (except for the rather peculiar case of negative d, or anti-persistence) under systematic sampling, implying that the finite-sample behaviour might differ substantially from that implied by theory. ${ }^{9}$

\section{Conclusions}

Despite the existence of a very extensive literature, there is still lack of consensus on what is the most appropriate specification for many financial series. For instance, whether asset returns of asset prices are predictable or not is still controversial: the efficiency market hypothesis suggests that they should follow a random walk (see

\footnotetext{
${ }^{7}$ When using the Abadir et al.'s (2007) approach, which is an extension of Robinson's (1995) that does not impose stationarity, the estimates were almost identical to those reported in the paper, and similar results were obtained with log-periodogram type estimators.

${ }^{8}$ Estimating $\mathrm{d}$ with the same bandwidth $\mathrm{m}=(\mathrm{T})^{0.5}$ produces evidence of unit roots in all series except the data collected at the 10-minute frequency.

${ }^{9}$ The sample size is large enough to justify the use of the asymptotic methods employed in this paper.
} 
Fama, 1970), but mean reversion is often found (see, e.g., Poterba and Summers, 1988). More recently, it has become clear that it is essential to consider the possibility of fractional integration in order to analyse the long-memory properties and to allow for a much richer dynamic specification. Various models have been suggested, increasingly general (see, e.g., Caporale and Gil-Alana, 2002, 2007, 2008). The first contribution of the present study is to show that indeed exchange rates dynamics may incorporate long memory components. A potentially crucial issue which has been overlooked is the extent to which the fractional differencing parameter might be sensitive to the data frequency. The second contribution of this paper is to examine this issue empirically using high frequency data on the US dollar-British pound spot exchange rate. In particular, we examined intra-day data (collected every 1, 2, 3, 5 and 10 minutes) for the open, close, high and low values of the exchange rate. In brief, we find evidence that a lower degree of integration is associated with lower data frequencies, and this holds for all the sample periods examined. In particular, when the data are collected every 10 minutes there are several cases with values of $d$ strictly smaller than 1 , implying a certain degree of mean-reverting behaviour; however, for higher data frequencies the unit root null cannot be rejected. This is the case for all the four series examined, and for different periods within the sample.

The above results indicate that the order of integration of a time series observed at different intervals may differ. There is no an obvious argument to justify this result. One possibility could be that the data generating process changes with the sampling frequency, although Hassler (2011) showed that this argument is not very strong as in the case of nonstationary fractional integration many of the basic time series properties are preserved under skip sampling. A more plausible argument could be the existence of a bias in the estimation results. Here we have two potential biases. One arises from 
temporal aggregation as suggested by Souza and Smith (2002). ${ }^{10}$ A second type of bias may arise from the high frequency of the data. It is well known that in this case there is microstructure noise and that this noise component becomes stronger as the sampling frequency increases. In the context of the semiparametric log-periodogram estimator Sun and Phillips (2003) derived an explicit form for this bias, which is negative and increases in absolute value as the variance of the noise increases. Sun and Phillips (2004) conjecture that the bias for Whittle-type estimators should be similar. Thus, we have two potential forces that move the bias in opposite directions. Which bias dominates in the case of the methods employed in the present study will be examined in future papers.

In essence, the results suggest that series that are expected to be I(1) consistently with market efficiency might not be so if the sampling frequency is high. Thus, for the 10-minute data, the unit root hypothesis is rejected in favour of mean reversion, Although this does not necessarily imply that the market is inefficient, since the assumption of a random walk is merely a sufficient but not a necessary condition for the EMH. $^{11}$

Finally, it might be asked whether the lower degrees of dependence observed at the lower frequencies is the result of small sample bias. However, it should be noted that even at the lowest data frequencies the sample size is large enough to justify the estimation of a fractional integration model. Extending the dataset to longer periods of time produced very similar results at a high computational cost (all computations were obtained using Fortran and the codes of the programs are available from the authors upon request). Other approaches could be applied to these and other high frequency data

\footnotetext{
${ }^{10}$ These authors investigated this bias for parametric and semiparametric estimates of $d$ and showed that the estimates decreased to zero as the sampling frequency decreases.

${ }^{11}$ Note that some of the findings in this paper suggest that the absolute and the squared returns are I(d) with $\mathrm{d}$ positive and small, which makes the assumption of a constant variance also questionable.
} 
such as the one suggested by Ohanissian et al. (2008) in their study on fractional integration, structural breaks and data frequency. Note that fractional integration and structural breaks are issues which are intimately related, but the latter is not relevant in the case of high frequency data as those used in this study. 


\section{References}

Abadir, K.M., W. Distaso and L. Giraitis, 2007, Nonstationarity-extended local Whittle estimation, Journal of Econometrics 141, 1353-1384.

Aloy, M., M. Booutahar, K. Gente and A. Peguin-Feissolle, 2011, Purchasing power parity and the long memory properties of real exchange rates. Economic Modelling 28, $1279-1290$

Baum, C.F., J. Barkoulas and M. Caglayan (1999) Persistence in the international inflation rates. Southern Economic Journal 65, 900-913.

Bloomfield, P., 1973, An exponential model in the spectrum of a scalar time series, Biometrika 60, 217-226.

Bollerslev, T., Wright, J.H., 2000, High frequency data, frequency domain inference and volatility forecasting, Review of Economics and Statistics 83, 596-602.

Booth, G.G., F.R. Kaen and P.E. Koveos (1982) R/S analysis of foreign exchange markets under two international monetary regimes. Journal of Monetary Economics 10, 407-415.

Caporale, G.M. and L.A. Gil-Alana, 2002, Fractional integration and mean reversion in stock prices, Quarterly Review of Economics and Finance 42, 599-609.

Caporale, G.M. and L.A. Gil-Alana, 2007, Long run and cyclical dynamics in the US stock market, CESifo Working Paper no. 2046.

Caporale, G.M. and L.A. Gil-Alana (2008), "Modelling long-run trends and cycles in financial time series data", CESifo Working Paper no. 2330.

Caporale, G.M. and L.A. Gil-Alana (2010) Fractional integration and data frequency, Journal of Statistical Computation and Simulation 80, 2, 121-132.

Cheung, Y.W. (1993) Long memory in foreign exchange rates. Journal of Business and Economic Statistics 11, 93-101. 
Cotter, J., 2005, Uncovering long memory in high frequency UK futures, European Journal of Finance 11, 325-337.

Crato, N. and B.K. Ray (2000) Memory in returns and volatilities of future's contracts. Journal of Futures Markets 20, 525-543.

Dahlhaus, R (1989). Efficient parameter estimation for self-similar process, Annals of Statistics, 17, 1749-1766.

Demetrescu, M., V. Kuzin and U. Hassler, 2008, Long memory testing in the time domain, Econometric Theory 24, 176-215.

Ding, Z., Granger, C.W.J., Engle, R.F., 1993, A long memory property of stock markets and a new model, Journal of Empirical Finance 1, 83-106.

Dufrenot, G., L. Mathieu, V. Mignon and A. Peguin-Feissolle, 2006, Persistent misalignments of the European exchange rates. Some evidence from nonlinear cointegration, Applied Economics 38, 203-229.

Dufrenot, G., s. Lardic, L. Mathieu, V. Mignon and A. Peguin-Feissolle, 2008, Explaining the European exchange rate deviations. Long memory or nonlinear adjustment, Journal of International Financial Markets, Institutions and Money 18, 207215.

Fama, E.F. (1970), "Efficient capital markets: a review of theory and empirical work", Journal of Finance, 25, 383-417.

Fama, E.F. and K.R. French, 1988, Permanent and transitory components of stock prices, Journal of Political Economy 96, 246-273.

Gil-Alana, Luis A. (2000), "Mean reversion in the real exchange rates", Economics Letters 69, 285-288.

Gil-Alana, L.A., 2003, Fractional integration in the volatility of asset returns, European Review of Economics and Finance 2, 41-52. 
Gil-Alana, L.A., 2005, Long memory in daily absolute and squared returns in the Spanish stock market, Advances in Investment Analysis and Portfolio Management 1, $198-217$.

Gil-Alana, L.A. and Robinson, P.M., 1997, Testing of unit roots and other nonstationary hypotheses in macroeconomic time series, Journal of Econometrics 80, 241-268.

Granger, C.W.J., 1980, Long memory relationships and the aggregation of dynamic models, Journal of Econometrics 14, 227-238.

Granger, C.W.J., Ding, Z., 1996, Varieties of long memory models, Journal of Econometrics 73, 61-78.

Hassler, U., 2011, Estimation of fractional integration under temporal aggregation, Journal of Econometrics 162, 240-247.

Lo, A., 1991, Long term memory in stock prices, Econometrica 59, 1279-1313.

Lobato, I.N., Savin, N.E., 1998, Real and spurious long memory properties of stock market data, Journal of Business and Economic Statistics 16, 261-268.

Lobato, I. and C. Velasco, 2007, Efficient Wald tests for fractional unit roots, Econometrica 75, 575-589.

Ohanissian, A. J.R. Russell and R.S. Tsay (2008), True or spurious long memory? A new test. Journal of Business and Economic Statistics, 26, 161-175.

Poterba, J. and L. Summers, 1988, Mean reversion in stock returns. Evidence and implications, Journal of Financial Economics 22, 27-60.

Robinson, P.M. (1978) Statistical inference for a random coefficient autoregressive model, Scandinavian Journal of Statistics 5, 163-168.

Robinson, P. M. (1994). Efficient tests of nonstationary hypotheses. Journal of the American Statistical Association, 89, 1420-1437. 
Robinson, P.M., 1995, Gaussian semi-parametric estimation of long range dependence, Annals of Statistics 23, 1630-1661.

Sibbertsen, P., 2004, Long memory in volatilities of German stock returns, Empirical Economics 29, 477-488.

Souza, L.R., (2005) A note on Chamber's long memory and aggregation in macroeconomic time series, International Economic Review 46, 3, 1059-1062.

Souza, L.R., 2007, Temporal aggregation and bandwidth selection in estimating long memory, Journal of Time Series Analysis 28, 701-722.

Souza, L.R., 2008A, Spectral properties of temporally aggregated long memory processes, Brazilian Journal of Probability and Statistics 22, 135-155.

Souza, L.R., 2008b, Why aggregate long memory time series?, Econometric Review 27, 298-336.

Souza, L.R. and J. Smith (2002) Bias in the memory parameter for different sampling rates, International Journal of Forecasting 18, 489-522.

Summers, L.H., 1986, Does the stock market rationally reflect fundamental values?, Journal of Finance 41, 591-601.

Sun, X. and P.C.B. Phillips (2003), Non-linear log-periodogram regression estimator for perturbed fractional processes, Journal of Econometrics 115, 355-389.

Sun, X. and P.C.B. Phillips (2004) Understanding the Fisher Equation, Journal of Applied Econometrics 19, 7, 869-896.

Wang, C. (2004) Futures trading activity and predictable foreign exchange movements. Journal of Banking and Finance 28, 1023-1041. 
Figure 1: Series in levels

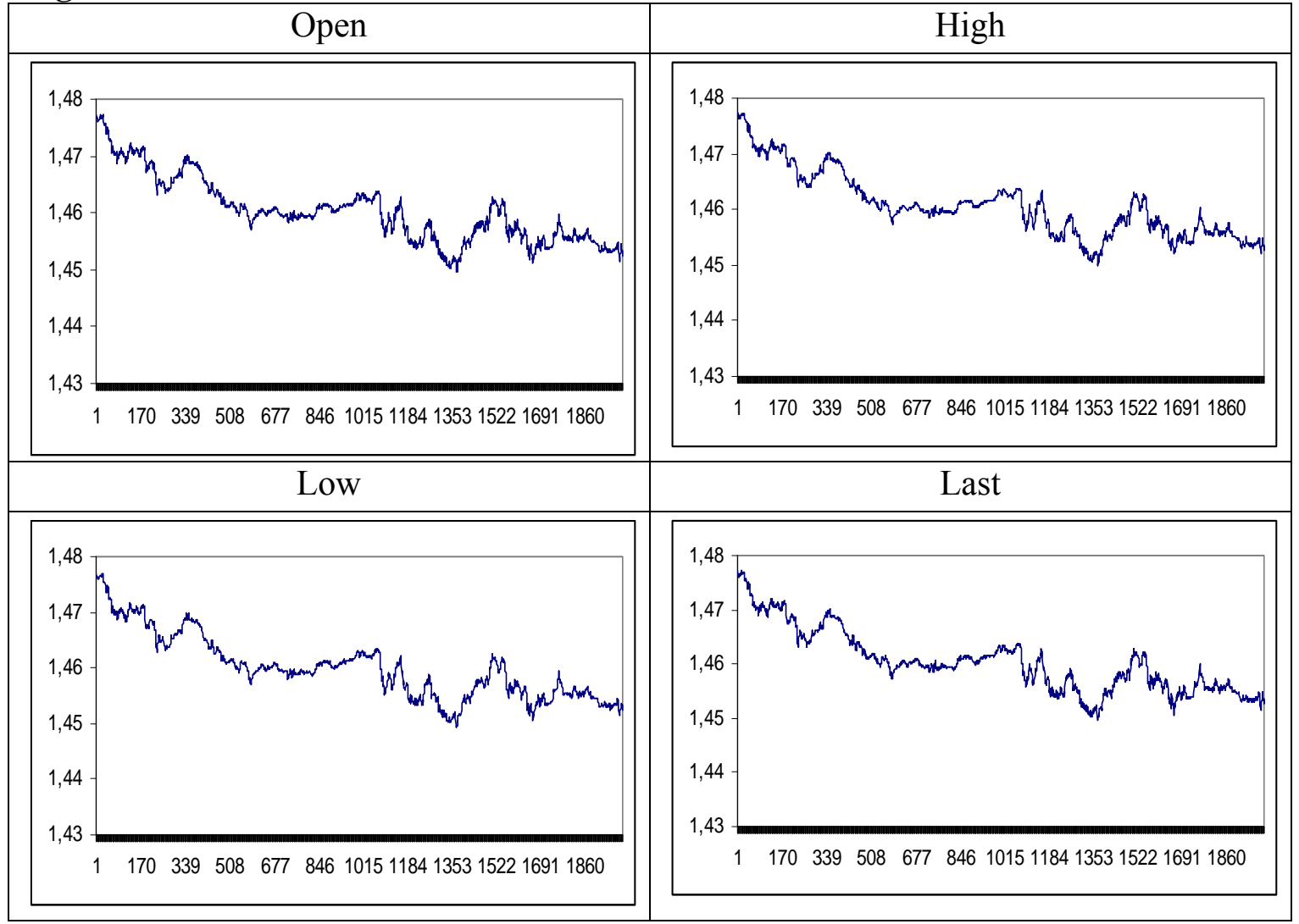

Figure 2: Returns

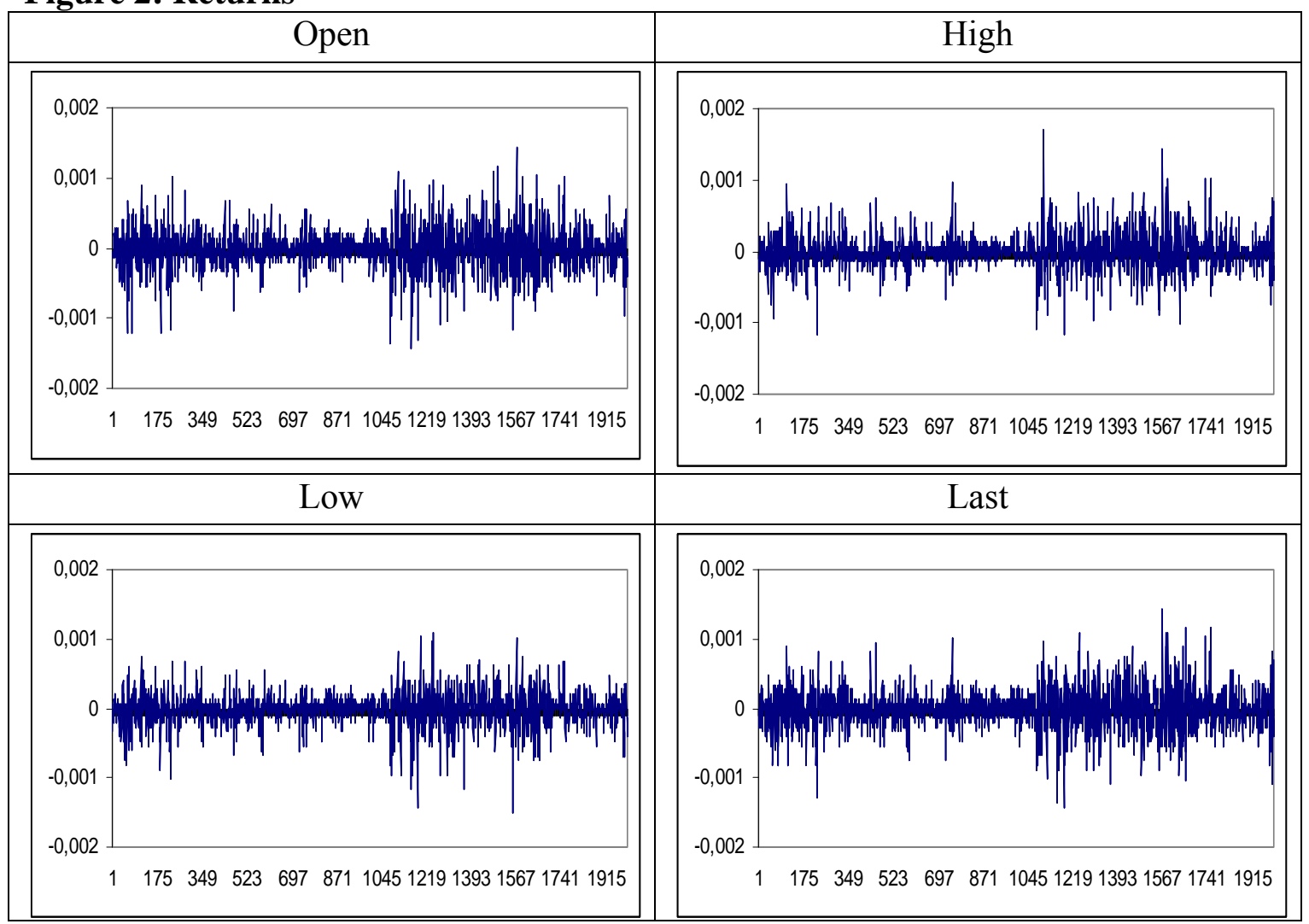


Figure 3: Correlograms of returns

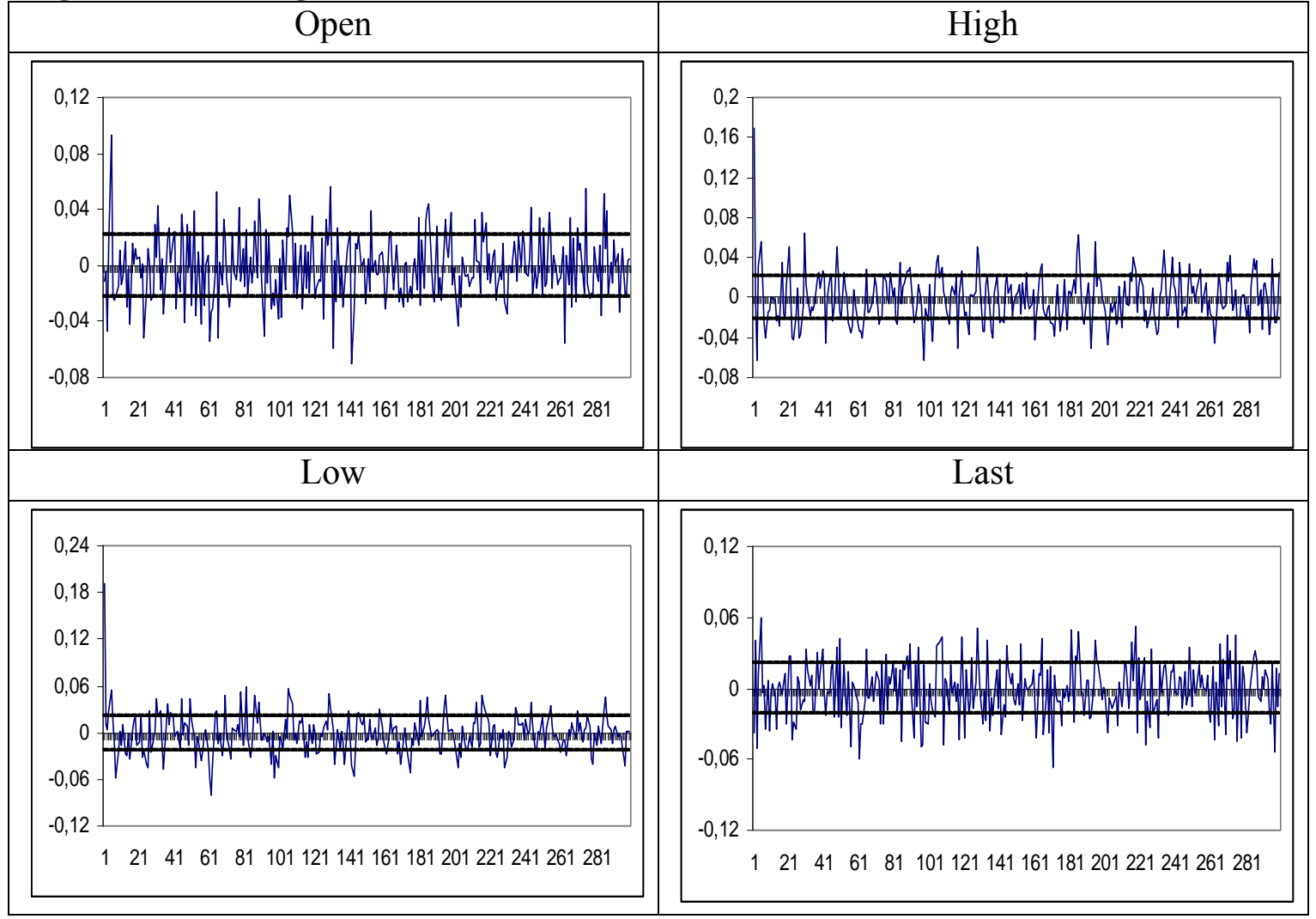

The thick lines refer to the $95 \%$ confidence band for the null hypothesis of no autocorrelation.

Figure 4: Periodograms of returns

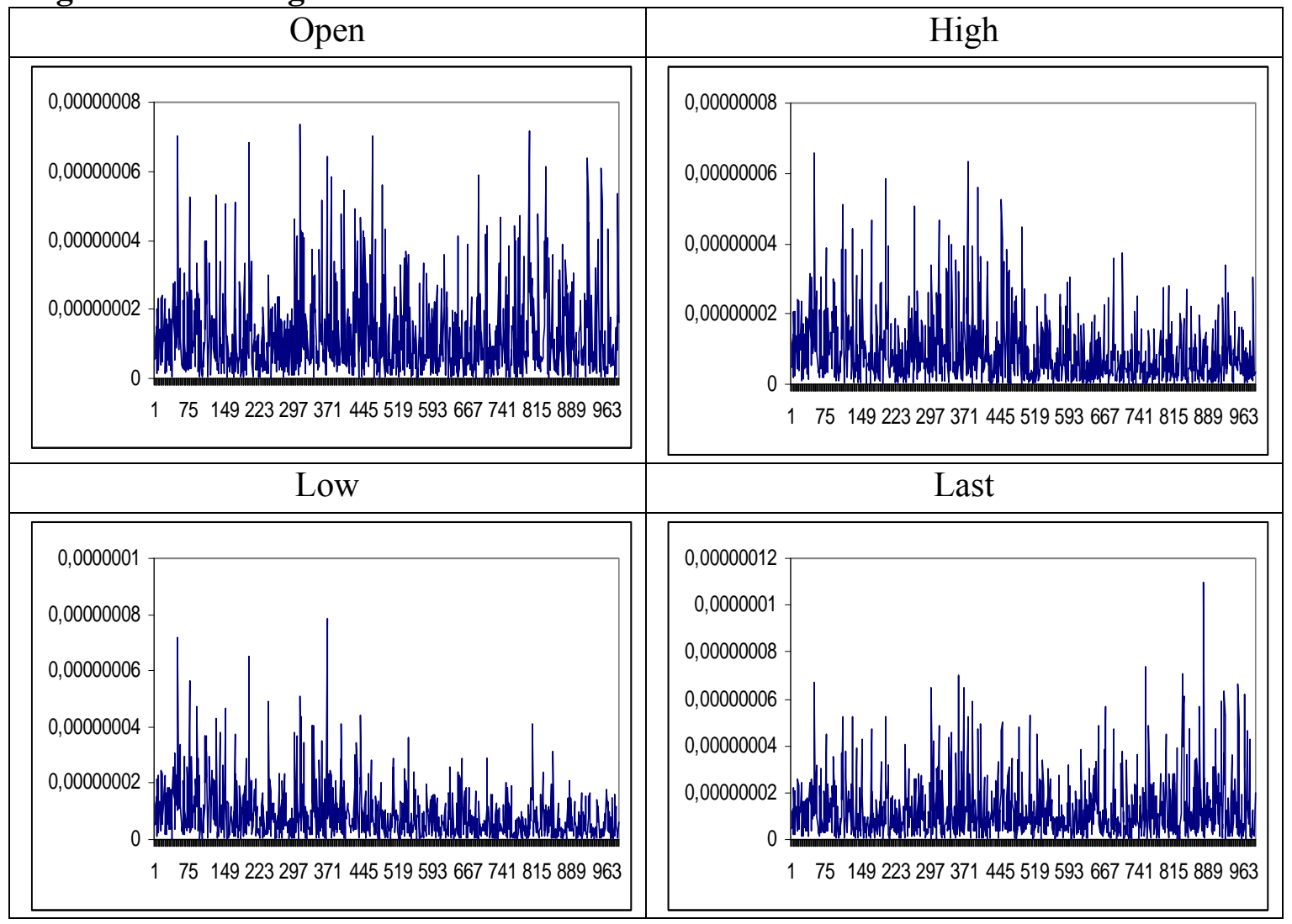

The horizontal axis refers to the discrete Fourier frequencies $\lambda_{j}=2 \pi j / T, j=1, \ldots, T / 2$. 
Table 1: Estimates of the fractional differencing parameter $d$

\begin{tabular}{|c|c|c|c|}
\hline \multicolumn{5}{|c|}{ a) White noise errors } \\
\hline Open & $0.997(0.970,1.027)$ & $0.983(0.955,1.015)$ & $0.983(0.956,1.015)$ \\
\hline High & $0.998(0.971,1.028)$ & $1.101(1.066,1.141)$ & $1.101(1.066,1.141)$ \\
\hline Low & $0.997(0.970,1.027)$ & $1.130(1.095,1.169)$ & $1.130(1.095,1.169)$ \\
\hline Last & $0.998(0.970,1.028)$ & $0.977(0.950,1.007)$ & $0.977(0.950,1.007)$ \\
\hline \multicolumn{5}{|c|}{ b) AR $(1)$ errors } \\
\hline No regressors & An intercept & A linear time trend \\
\hline Open & $1.381(1.328,1.441)$ & $0.973(0.923,1.031)$ & $0.974(0.924,1.031)$ \\
\hline High & $1.382(1.329,1.442)$ & $0.934(0.879,0.996)$ & $0.936(0.883,0.996)$ \\
\hline Low & $1.381(1.327,1.440)$ & $0.969(0.907,1.037)$ & $0.970(0.910,1.037)$ \\
\hline Last & $1.382(1.329,1.442)$ & $1.004(0.954,1.060)$ & $1.004(0.955,1.060)$ \\
\hline \multicolumn{5}{|c|}{ c) Bloomfield-type errors } \\
\hline No regressors & An intercept & A linear time trend \\
\hline Open & $0.997(0.944,1.041)$ & $0.963(0.922,1.029)$ & $0.970(0.923,1.029)$ \\
\hline High & $0.991(0.950,1.042)$ & $0.962(0.914,1.006)$ & $0.962(0.915,1.006)$ \\
\hline Low & $0.990(0.951,1.047)$ & $0.988(0.939,1.047)$ & $0.988(0.940,1.047)$ \\
\hline Last & $0.998(0.950,1.049)$ & $1.010(0.955,1.057)$ & $1.010(0.955,1.057)$ \\
\hline
\end{tabular}

The values in parentheses give the $95 \%$ confidence band for the non-rejection values of $\mathrm{d}$. 
Figure 5: Absolute returns

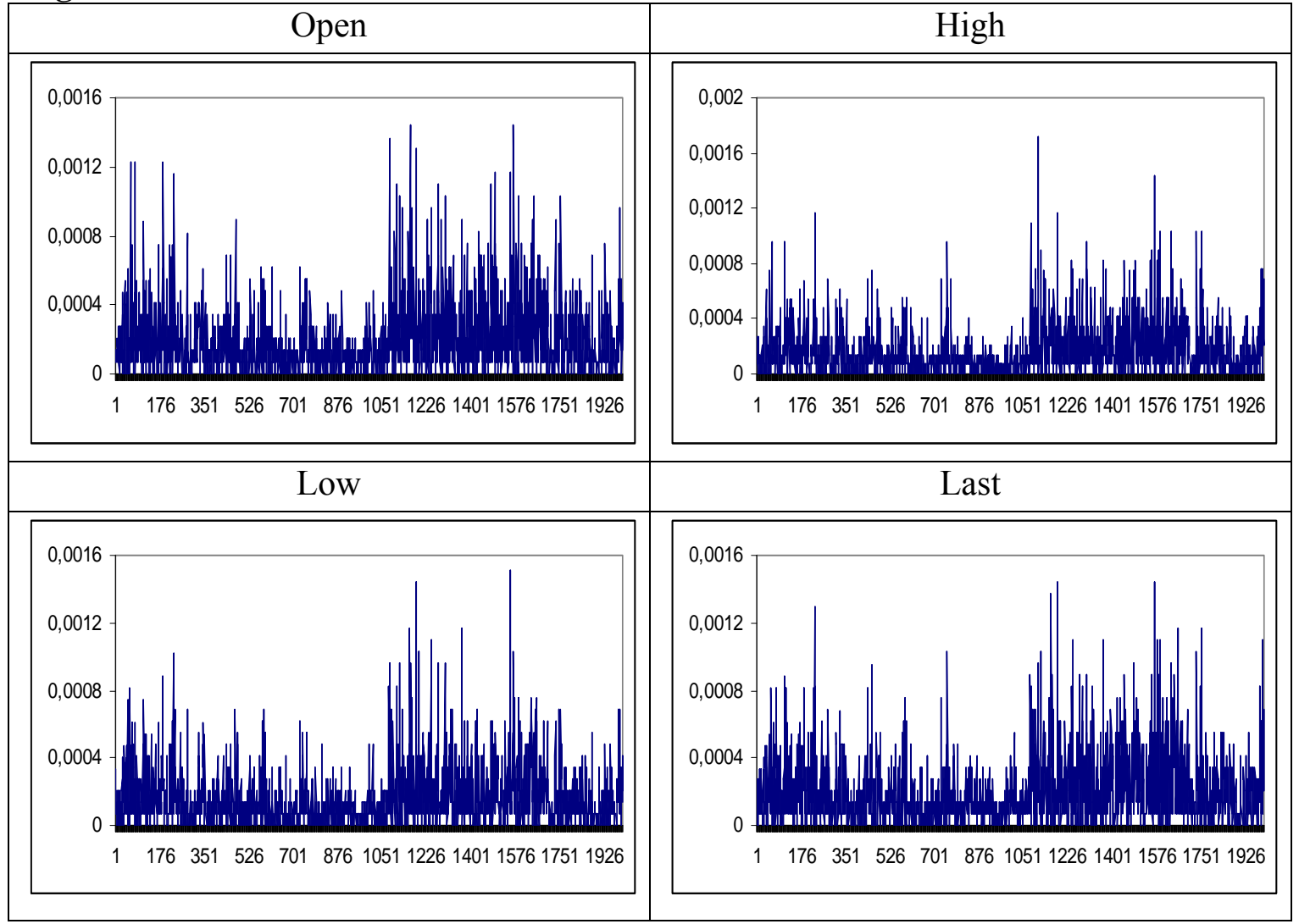

Figure 6: Squared returns

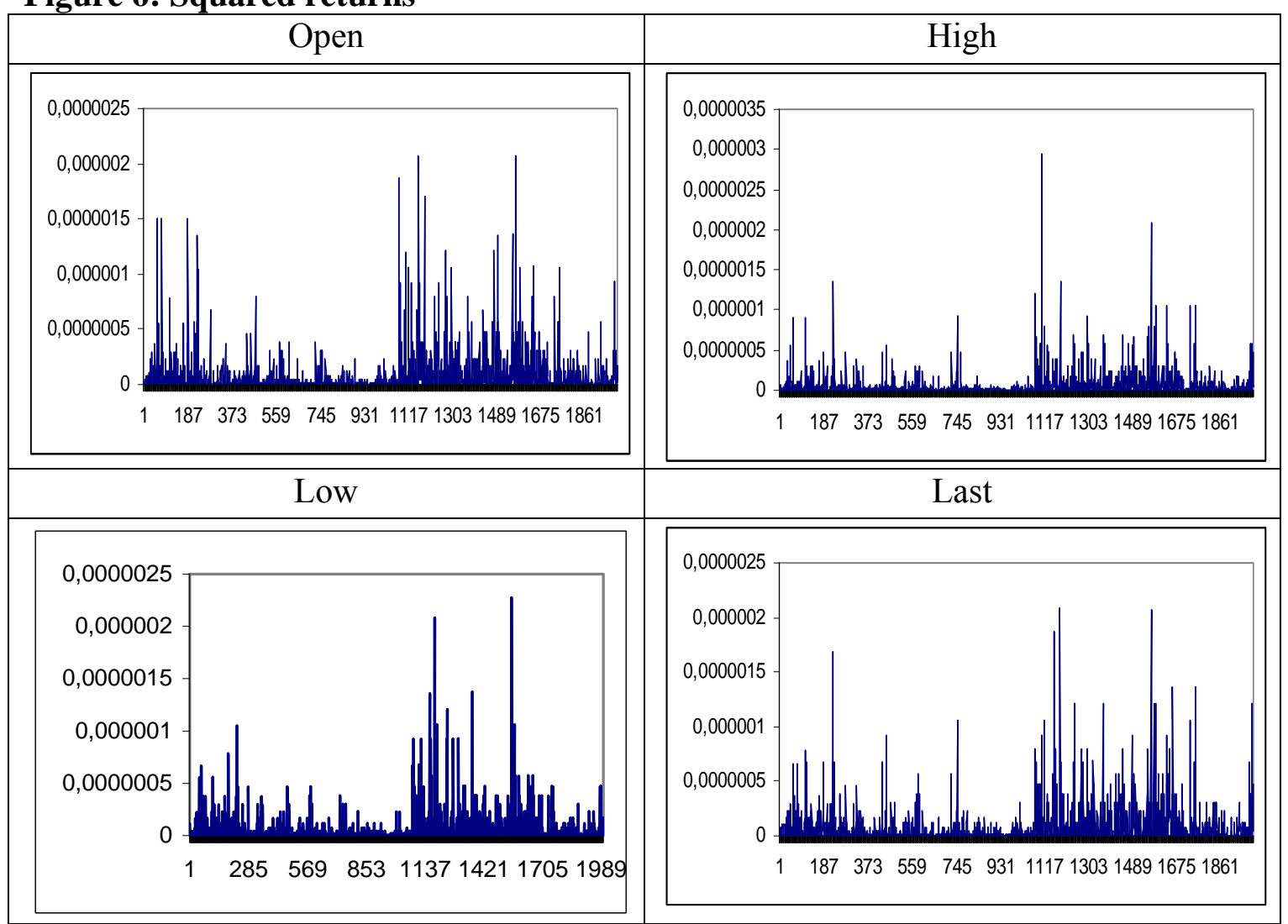


Table 2: Estimates of $\mathbf{d}$ for the absolute and squared returns with white noise errors

\begin{tabular}{|c|c|c|c|}
\hline \multicolumn{5}{|c|}{ a) } & Absolute returns \\
\hline & No regressors & An intercept & A linear time trend \\
\hline Open & $0.149(0.131,0.171)$ & $0.148(0.130,0.168)$ & $0.144(0.126,0.165)$ \\
\hline High & $0.162(0.142,0.185)$ & $0.159(0.140,0.181)$ & $0.156(0.136,0.178)$ \\
\hline Low & $0.154(0.134,0.171)$ & $0.151(0.132,0.172)$ & $0.149(0.129,0.176)$ \\
\hline Last & $0.143(0.123,0.167)$ & $0.142(0.124,0.163)$ & $0.136(0.117,0.158)$ \\
\hline \multicolumn{5}{|c|}{ bo regressors } & Squared returns & An intercept \\
\hline Open & $0.106(0.088,0.126)$ & $0.107(0.089,0.127)$ & $0.103(0.085,0.124)$ \\
\hline High & $0.098(0.078,0.121)$ & $0.099(0.080,0.122)$ & $0.094(0.074,0.118)$ \\
\hline Low & $0.098(0.079,0.120)$ & $0.099(0.080,0.121)$ & $0.096(0.077,0.118)$ \\
\hline Last & $0.106(0.088,0.128)$ & $0.109(0.090,0.130)$ & $0.102(0.082,0.124)$ \\
\hline
\end{tabular}

The values in parentheses give the $95 \%$ confidence band for the non-rejection values of $\mathrm{d}$. 
Table 3: Estimates of the fractional differencing parameter based on white noise $u_{t}$

\begin{tabular}{|c|c|c|c|}
\hline \multicolumn{4}{|c|}{ a) 2 minutes } \\
\hline & No regressors & An intercept & A linear time trend \\
\hline Open & $0.994(0.956,1.038)$ & $0.980(0.939,1.028)$ & $0.980(0.940,1.028)$ \\
\hline High & $0.994(0.956,1.038)$ & $1.034(0.989,1.087)$ & $1.034(0.989,1.087)$ \\
\hline Low & $0.995(0.957,1.039)$ & $1.062(1.017,1.116)$ & $1.062(1.017,1.115)$ \\
\hline Last & $0.994(0.957,1.039)$ & $0.989(0.948,1.035)$ & $0.989(0.949,1.035)$ \\
\hline \multicolumn{4}{|c|}{ b) 3 minutes } \\
\hline & No regressors & An intercept & A linear time trend \\
\hline Open & $0.992(0.946,1.047)$ & $0.962(0.912,1.019)$ & $0.963(0.914,1.019)$ \\
\hline High & $0.992(0.946,1.047)$ & $1.003(0.950,1.066)$ & $1.003(0.951,1.065)$ \\
\hline Low & $0.993(0.947,1.048)$ & $1.041(0.984,1.108)$ & $1.041(0.985,1.107)$ \\
\hline Last & $0.992(0.946,1.048)$ & $0.958(0.907,1.016)$ & $0.958 \quad 0.910,1.016)$ \\
\hline \multicolumn{4}{|c|}{ c) 5 minutes } \\
\hline & No regressors & An intercept & A linear time trend \\
\hline Open & $0.990(0.930,1.064)$ & $0.941(0.872,1.024)$ & $0.942(0.877,1.024)$ \\
\hline High & $0.990(0.931,1.064)$ & $0.948(0.880,1.030)$ & $0.949(0.885,1.030)$ \\
\hline Low & $0.990(0.931,1.064)$ & $0.981(0.910,1.069)$ & $0.982(0.913,1.068)$ \\
\hline Last & $0.989(0.930,1.063)$ & $0.942(0.874,1.024)$ & $0.944(0.879,1.023)$ \\
\hline \multicolumn{4}{|c|}{ d) 10 minutes } \\
\hline & No regressors & An intercept & A linear time trend \\
\hline Open & $0.977(0.895,1.088)$ & $0.831(0.719,0.957)$ & $0.848(0.761,0.961)$ \\
\hline High & $0.978(0.895,1.089)$ & $0.869(0.766,0.990)$ & $0.881(0.794,0.991)$ \\
\hline Low & $0.977(0.895,1.088)$ & $0.860(0.750,0.987)$ & $0.873(0.784,0.988)$ \\
\hline Last & $0.978(0.895,1.089)$ & $0.861(0.755,0.983)$ & $0.872(0.785,0.985)$ \\
\hline
\end{tabular}

The values in parentheses give the $95 \%$ confidence band for the non-rejection values of $\mathrm{d}$. 
Table 4: Estimates of $\mathrm{d}$ for the absolute returns

\begin{tabular}{|c|c|c|c|}
\hline \multicolumn{4}{|c|}{ a) 2 minutes } \\
\hline & No regressors & An intercept & A linear time trend \\
\hline Open & $0.188(0.157,0.225)$ & $0.182(0.153,0.217)$ & $0.179(0.149,0.215)$ \\
\hline High & $0.181(0.152,0.216)$ & $0.179(0.151,0.211)$ & $0.174(0.146,0.208)$ \\
\hline Low & $0.176(0.148,0.210)$ & $0.171(0.144,0.202)$ & $0.168(0.141,0.200)$ \\
\hline Last & $0.143(0.116,0.173)$ & $0.140(0.116,0.169)$ & $0.136(0.111,0.166)$ \\
\hline \multicolumn{4}{|c|}{ b) 3 minutes } \\
\hline & No regressors & An intercept & A linear time trend \\
\hline Open & $0.159(0.124,0.202)$ & $0.157(0.124,0.197)$ & $0.151(0.116,0.192)$ \\
\hline High & $0.178(0.143,0.221)$ & $0.176(0.143,0.216)$ & $0.171(0.136,0.212)$ \\
\hline Low & $0.165(0.127,0.212)$ & $0.159(0.124,0.202)$ & $0.156(0.120,0.200)$ \\
\hline Last & $0.167(0.131,0.211)$ & $0.168(0.135,0.210)$ & $0.160(0.124,0.204)$ \\
\hline \multicolumn{4}{|c|}{ c) 5 minutes } \\
\hline & No regressors & An intercept & A linear time trend \\
\hline Open & $0.189(0.140,0.247)$ & $0.176(0.133,0.231)$ & $0.175(0.131,0.230)$ \\
\hline High & $0.194(0.144,0.259)$ & $0.190(0.144,0.249)$ & $0.186(0.138,0.247)$ \\
\hline Low & $0.216(0.165,0.281)$ & $0.203(0.157,0.262)$ & $0.202(0.155,0.261)$ \\
\hline Last & $0.149(0.106,0.204)$ & $0.150(0.109,0.202)$ & $0.144(0.102,0.198)$ \\
\hline \multicolumn{4}{|c|}{ d) 10 minutes } \\
\hline & No regressors & An intercept & A linear time trend \\
\hline Open & $0.143(0.077,0.233)$ & $0.136(0.076,0.213)$ & $0.133(0.071,0.212)$ \\
\hline High & $0.088(0.028,0.174)$ & $0.086(0.028,0.161)$ & $0.084(0.025,0.160)$ \\
\hline Low & $0.133(0.058,0.233)$ & $0.121(0.055,0.207)$ & $0.121(0.054,0.207)$ \\
\hline Last & $0.088(0.024,0.176)$ & $0.083(0.024,0.156)$ & $0.083(0.024,0.160)$ \\
\hline
\end{tabular}

The values in parentheses give the $95 \%$ confidence band for the non-rejection values of $\mathrm{d}$. 
Table 5: Estimates of $\mathbf{d}$ for the squared returns

\begin{tabular}{|c|c|c|c|}
\hline \multicolumn{4}{|c|}{ a) 2 minutes } \\
\hline & No regressors & An intercept & A linear time trend \\
\hline Open & $0.129(0.096,0.164)$ & $0.130(0.101,0.164)$ & $0.126(0.100,0.162)$ \\
\hline High & $0.115(0.087,0.149)$ & $0.118(0.090,0.151)$ & $0.110(0.080,0.145)$ \\
\hline Low & $0.113(0.086,0.145)$ & $0.115(0.088,0.146)$ & $0.111(0.083,0.143)$ \\
\hline Last & $0.097(0.072,0.127)$ & $0.100(0.075,0.129)$ & $0.093(0.067,0.124)$ \\
\hline \multicolumn{4}{|c|}{ b) 3 minutes } \\
\hline & No regressors & An intercept & A linear time trend \\
\hline Open & $0.106(0.073,0.148)$ & $0.108(0.075,0.149)$ & $0.103(0.068,0.145)$ \\
\hline High & $0.123(0.090,0.165)$ & $0.125(0.092,0.166)$ & $0.119(0.084,0.161)$ \\
\hline Low & $0.128(0.089,0.176)$ & $0.129(0.091,0.176)$ & $0.126(0.087,0.174)$ \\
\hline Last & $0.126(0.090,0.171)$ & $0.130(0.094,0.174)$ & $0.123(0.084,0.169)$ \\
\hline \multicolumn{4}{|c|}{ c) 5 minutes } \\
\hline & No regressors & An intercept & A linear time trend \\
\hline Open & $0.136(0.088,0.198)$ & $0.135(0.089,0.195)$ & $0.133(0.085,0.194)$ \\
\hline High & $0.144(0.094,0.210)$ & $0.147(0.097,0.211)$ & $0.141(0.089,0.208)$ \\
\hline Low & $0.160(0.111,0.224)$ & $0.159(0.111,0.221)$ & $0.157(0.108,0.220)$ \\
\hline Last & $0.110(0.067,0.166)$ & $0.113(0.070,0.169)$ & $0.107(0.061,0.164)$ \\
\hline \multicolumn{4}{|c|}{ d) 10 minutes } \\
\hline & No regressors & An intercept & A linear time trend \\
\hline Open & $0.088(0.027,0.171)$ & $0.090(0.028,0.171)$ & $0.085(0.021,0.168)$ \\
\hline High & $0.044(-0.015,0.125)$ & $0.045(-0.016,0.127)$ & $0.041(-0.023,0.125)$ \\
\hline Low & $0.083(0.019,0.177)$ & $0.084(0.020,0.169)$ & $0.082(0.016,0.168)$ \\
\hline Last & $0.049(-0.011,0.132)$ & $0.051(-0.011,0.133)$ & $0.049(-0.015,0.132)$ \\
\hline
\end{tabular}

The values in parentheses give the $95 \%$ confidence band for the non-rejection values of $\mathrm{d}$. 
Figure 7: Estimates of $\mathbf{d}$ for the OPEN series for different bandwidth parameters
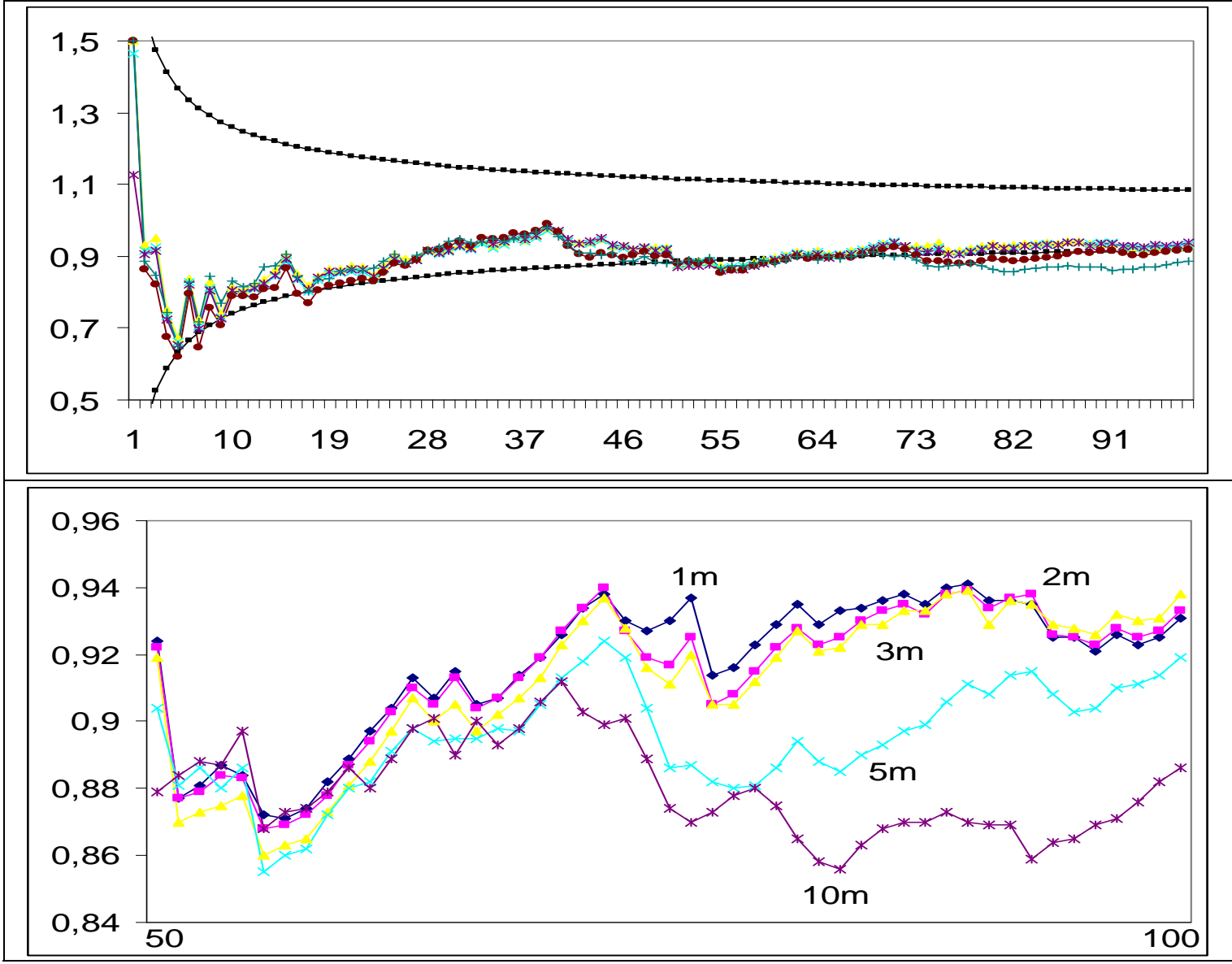

The horizontal axis concerns the bandwidth parameter while the vertical one refers to the estimated value of d. 
Figure 8: Estimates of $d$ for the HIGH series for different bandwidth parameters
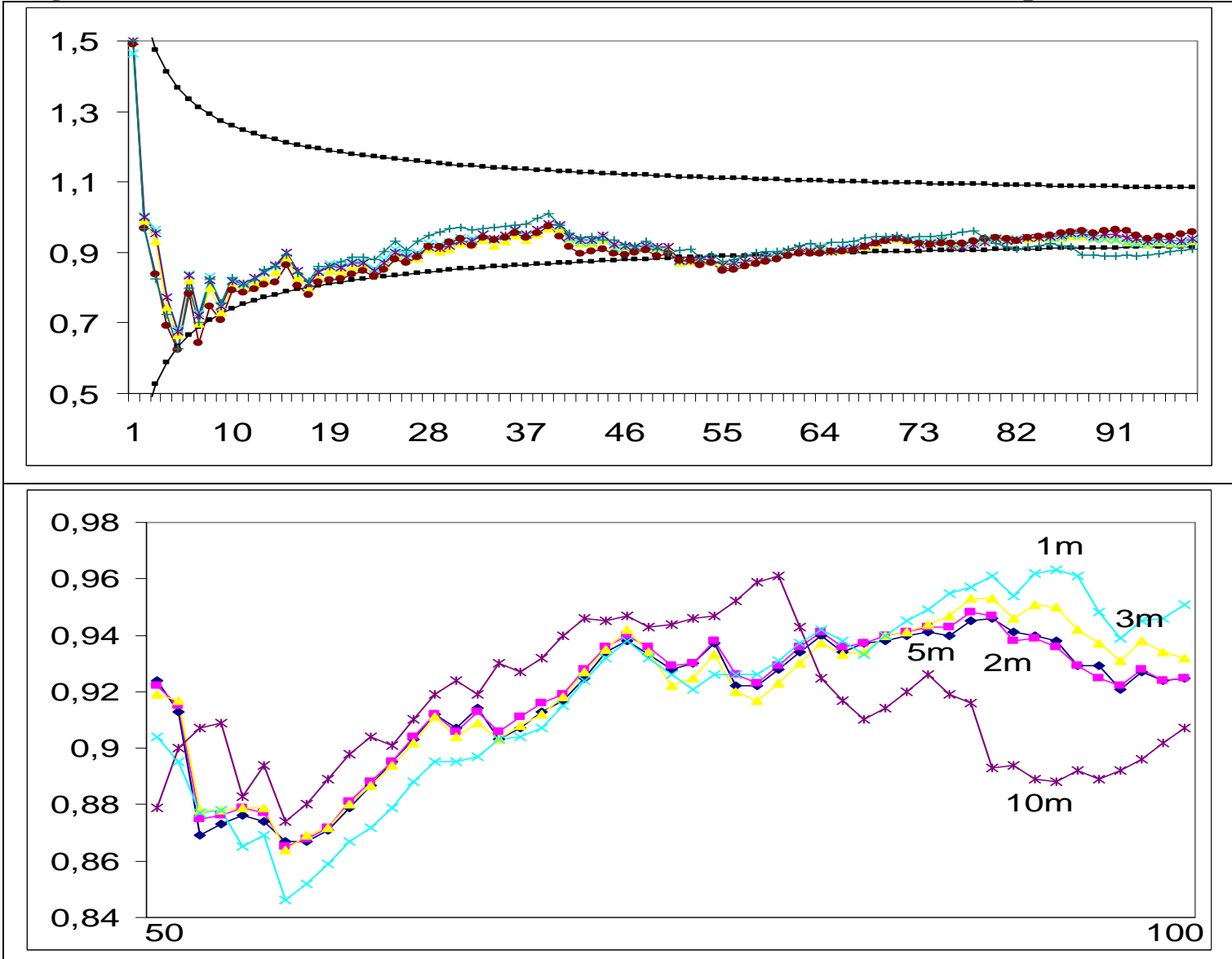

The horizontal axis concerns the bandwidth parameter while the vertical one refers to the estimated value of d. 
Figure 9: Estimates of $d$ for the LOW series for different bandwidth parameters

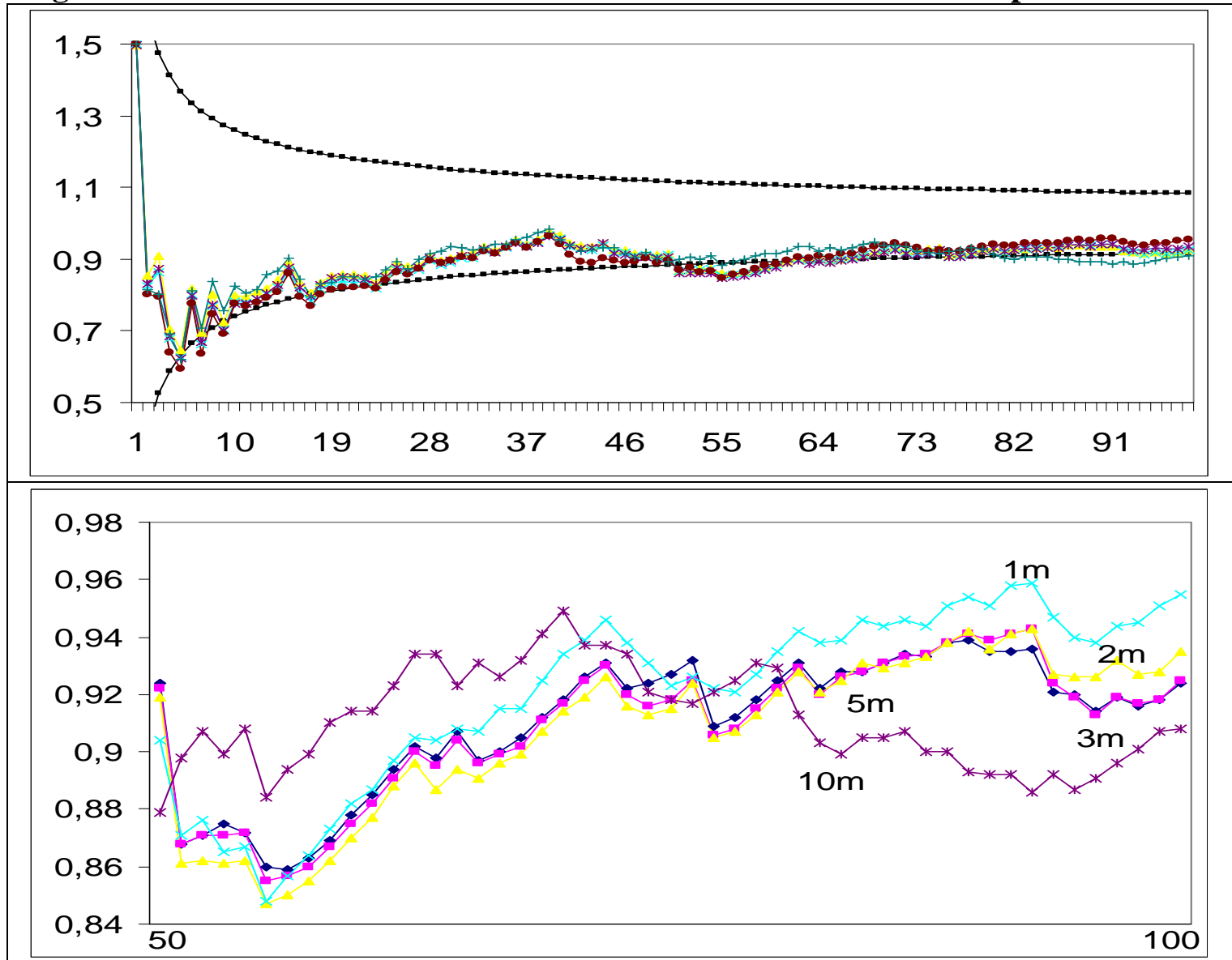

The horizontal axis concerns the bandwidth parameter while the vertical one refers to the estimated value of d. 
Figure 10: Estimates of $d$ for the LAST series for different bandwidth parameters

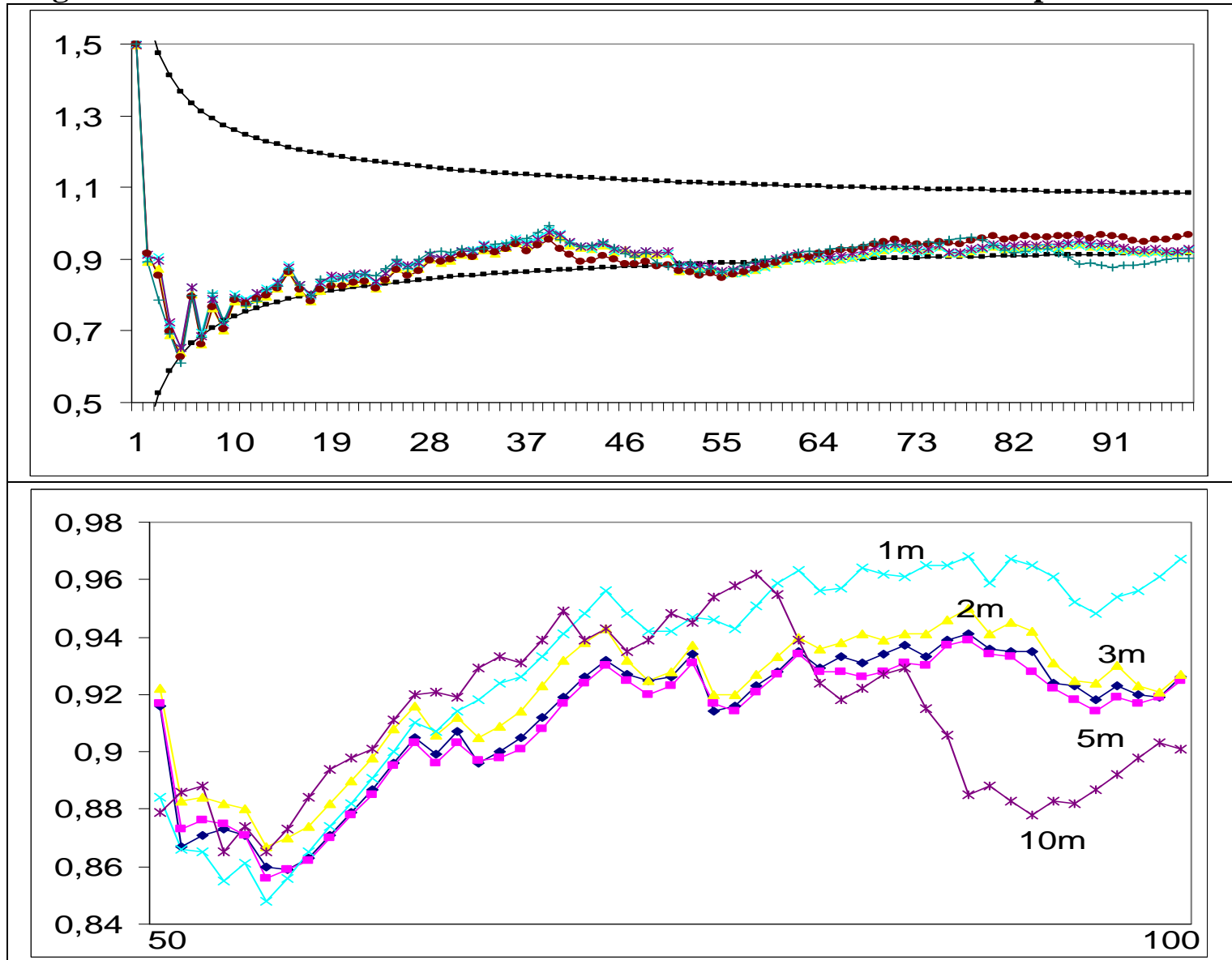

The horizontal axis concerns the bandwidth parameter while the vertical one refers to the estimated value of d. 